\title{
Glioneuronal Tumor with Neuropil-Like Islands
}

National Cancer Institute

\section{Source}

National Cancer Institute. Glioneuronal T umor with Neuropil-Like Islands. NCI Thesaurus.

Code C92550.

A rare, WHO grade II or III infiltrating astrocytoma characterized by the presence of sharply demarcated foci, composed of a neuropil-like matrix. 